irrespective of industries. They are forced to work in cramped space assuming awkward posture that burden to cardio-respiratory system.

Methods This study was performed on worker $(n=31)$ engaged in welding job in different construction industry throughout West Bengal. The task was examined in the light of the observed physiological parameters and postural load in workers during their performances. The physical strain in terms of cardio-acceleration and energy cost was examined by Heart Rate Monitor. Ergonomic assessment tool REBA (Rapid Entire Body Assessment) was used to assess the working posture and risk level of postural load. Different thermal factors like Dry bulb temperature(DB), Wet bulb temperature(WB), Globe temperature(GT), Relative humidity(RH), Air velocity (AV), Wet bulb globe temperature(WBGT) was evaluated.

Result Cardio-acceleration and energy cost was found to be moderately heavy. Risk level of postural load was found to be 4-9 category. DB $\left(32.27^{\circ} \mathrm{C}-35.7^{\circ} \mathrm{C}\right)$, WB $\left(23.92^{\circ} \mathrm{C}-26.5^{\circ} \mathrm{C}\right)$, GT $\quad\left(36.73^{\circ} \mathrm{C}-40.73^{\circ} \mathrm{C}\right), \quad$ RH $\quad(43.27 \%-49.9 \%), \quad$ AV $\quad(15.56$ meter/minute-26.67 meter/minute), WBGT $\left(27.23^{\circ} \mathrm{C}-30.2^{\circ} \mathrm{C}\right)$ was found.

Discussion It was observed that the workers were suffering from huge amount of postural load and also encountered with radiant heat from work environment which turns the work more strenuous for them. It is urgently necessary to consider some interventions which may limit the environmental stress and postural load to increase the productivity of welders.

\section{DIAGNOSIS, PREVENTION AND COMPENSATION OF OCCUPATIONAL DISEASES IN THE RUSSIAN FEDERATION}

I Bukhtiyarov. FSBSI 'Izmerov Research Institute of Occupational Health', Moscow, Russia

\subsection{6/oemed-2018-ICOHabstracts.896}

In the countries of EU simultaneously act several lists of occupational diseases (OD) (opened, closed, closed regulated). National list of OD in the Russian Federation (RF) is opened type. In common RF OD list is harmonised with ILO OD list (revised 2010) with some exceptions. For example, National OD list does not recognise work related diseases.

The dynamics of the number of cases of OD in the RF in 2011-2015 and OD level (per 100 thousand people) and their trends for 2016-2030 were studied compared to the level of OD in the EU countries-27. In 2011 the number of new cases of OD was 8923 (the population were 142.9 million people); in 2015г. the number of detected cases of occupational diseases was 7410 (the population were 146.3 million people). The level of OD was decreased from 6.24 (2011) up to 5.06 (2015) per 100 thousand people. The analysis of OD level shows that the number of detected cases of OD for the first time in the RF was significant (7-8 times) lower than in UN countries-27-40.07 per 100 thousand population (2014).

Structure of OD in RF shows than maximal part of OD are diseases caused by physical agents (48.85\%), hearing impairment caused by noise and disease caused by vibration including. The another main ODs were: ODs caused by chemical agents as well as occupational respiratory and occupational skin diseases. There are absent post-traumatic stress disorders and dramatic low level of occupational cancer. Over 20022014 , total of 498 cases of occupational cancer was registered, that is less than $0,3 \%$ of minimal expected number of cases.
This is connected with peculiarities of OD registration system and underestimation real level of OD. All this justifies the need of occupational diseases diagnosis, prevention and compensation system improving in the RF.

\section{SYSTEMATIC OCCUPATIONAL HEALTH ENHANCEMENT LEVEL PROGRAMME - TOWARDS ACHIEVING OSH MASTER PLAN 2020 BY ENHANCING INDUSTRIAL HYGIENE IN MALAYSIA}

A Ahmad Fitri*, A Majahar, C Husdin, M Zabidi. Department Of Occupational Safety And Health Malaysia, Putrajaya, Federal Territory of Putrajaya, Malaysia

\subsection{6/oemed-2018-ICOHabstracts.897}

Introduction Systematic Occupational Enhancement Level Programme (SoHELP) is a systematic intervention programme which focus to help industries in Malaysia to enhance industrial hygiene and occupational health standard in the workplaces and to meet the regulatory requirements on industrial hygiene related regulations. The development of this programme are based on the increasing trend on reported occupational diseases in Malaysia and relatively low compliance to industrial hygiene related regulations which industrial hygiene related regulations seems as difficult and costly to comply compare to industrial safety regulations. The basis of the programme are focusing on three (3) main occupational hazards which are mainly due to exposure to excessive noise, chemical and ergonomic risk factor at the workplace.

Methods The participation of the industries into this programme are voluntarily and they should have safety and health officer as person in charge to coordinate the programme at their workplace. The department has developed the module based on this three (3) main occupational hazard which the industries need to comply and implemented at their workplace with given time of 14 months from 1 st April 2016 until 31 st May 2017.

Results The programme have been successfully being implemented to 214 workplaces which involved 261 Occupational Safety and Health (OSH) Practitioner and 139855 workers in Malaysia. The overall achievement and compliance based on implementation of the programme are 3.9/5.0 (78\%).

Conclusion This programme has been included in the Occupational Safety and Health Master Plan 2016-2020 (OSH-MP 2020) for Malaysia and been part of national platform for strategic and synergistic cooperation between government, employers, OSH practitioners, and employees to enhance industrial hygiene and health standard in the workplaces and as part of preventive tools to reduce the numbers of occupational diseases at the workplace.

\section{CANTEEN HYGIENE INDEX IN INDIANOIL}

Sandeep Sharma*, SK Awasthi. IndiaOil Corporation Ltd, New Delhi, India

\subsection{6/oemed-2018-ICOHabstracts.898}

Introduction Organisations provides and maintains canteens at their offices and installations. Employees eat food in these canteens while they are in office. For maintaining good health, it is essential to have a well-balanced nutritious diet from these canteens. 